\title{
Association of the Genetic Polymorphisms for CD247 Gene and Tuberculosis Case
}

\author{
Yeongdon $\mathrm{Ju}^{1, *}$, Sung-Soo Kim ${ }^{2, *}$, Kyung Eun Lee ${ }^{1, * *}$, Sangjung Park ${ }^{2, \dagger, * *}$ and Hyunwoo Jin ${ }^{1, \dagger, * *}$ \\ ${ }^{1}$ Department of Clinical Laboratory Science, College of Health Sciences, \\ Catholic University of Pusan, Busan 46252, Korea \\ ${ }^{2}$ Department of Biomedical Laboratory Science, College of Life and Health Sciences, \\ Hoseo University, Asan, Chungnam 31499, Korea
}

Tuberculosis is airborne disease caused by Mycobacterium tuberculosis (MTB). Host genetic factors of these tuberculosis play an important role in determining individual difference in susceptibility or resistance to infectious diseases including tuberculosis. CD247 is named CD3zeta chain or CD3 6 . CD247 gene is a protein-coding gene involved in phagocytosis and signal transduction of the $\mathrm{T}$ cell receptor (TCR). Also, downregulation of the $\mathrm{CD} 3 \zeta$ chain has been associated to chronic inflammation. The aim of this study was to research association of the genetic polymorphisms for CD247 gene and tuberculosis. We analyzed association of CD247 and Mycobacterium tuberculosis using 149 imputed single nucleotide polymorphisms (SNPs) with Korean population. And the results of this study show that seven SNPs of CD247 were identified to associate with tuberculosis. The most significant SNP was rs858545 (OR=1.22, CI: 1.05 1.42, $P=0.009481$ ). This study suggests that polymorphisms of $C D 247$ may affect the T cell receptor signaling pathway, which may associate the infection of tuberculosis.

Key Words: Tuberculosis, CD247, Genetic analysis, Mycobacterium tuberculosis

\section{서 론}

결핵은 Mycobacterium tuberculosis (MTB)에 의해 발생하 는 질병으로 주로 호흡기에 의해 전파되며 보통 폐에 영 향을 미쳐 심각한 기침, 열, 및 흉통을 유발하고, HIV/ AIDS에 이어 사망률이 두 번째로 높은 질병이다(Fogel, 2015; Algood et al., 2003). 건강보험심사평가원 보건의료빅 데이터개방시스템에 따르면 2019년 6월 기준 우리나라의

Received: March 2, 2020 / Accepted: March 24, 2020

*Ungraduate student, ${ }^{* *}$ Professor.

${ }^{\dagger}$ These authors are equally contributed.

${ }^{\dagger}$ Corresponding author: Sangjung Park. Department of Biomedical Laboratory Science, College of Life and Health Sciences, Hoseo University, Asan, Chungnam 31499, Korea.

Tel: +82-41-540-9967, Fax: +82-41-540-9997, e-mail: sangjung@hoseo.edu

${ }^{\dagger}$ Corresponding author: Hyunwoo Jin. Department of Clinical Laboratory Science, College of Health Science, Catholic University of Pusan, Busan 46252, Korea.

Tel: +82-51-510-0567, Fax:+82-51-510-0568, e-mail: jjinhw@cup.ac.kr

(OThe Korean Society for Biomedical Laboratory Sciences. All rights reserved.

(9)This is an Open Access article distributed under the terms of the Creative Commons Attribution Non-Commercial License (http://creativecommons.org/licenses/by-nc/3.0/) which permits unrestricted non-commercial use, distribution, and reproduction in any medium, provided the original work is properly cited.
결핵 환자수는 경기 3,735 명, 서울 3,095 명, 부산 1,234 명 등 총 16,980명으로 나타났다(HIRA, 2019). 2011년부터 2016년까지 새로 보고된 우리나라의 결핵 발병률은 매년 감소하였지만 고소득 국가 중 결핵 발병률 및 사망률은 가장 높은 것으로 나타났다(Min et al., 2019). 이러한 결핵 의 발병은 결핵을 포함하여 감염성 질환에 대해 개인의 유전자 차이로 감수성 또는 저항성을 결정하는데 중요한 역할을 한다(Harishankar et al., 2018). 따라서 결핵과 유전적 요인의 연관성에 대한 연구 또한 많이 진행되고 있다. 
$\mathrm{CD} 3$ complex를 형성하는 $C D 247$ 유전자는 CD3zeta chain 및 $\mathrm{CD} 3$ 로 명명되고 있는 유전자로 염색체 1q24.2에 위 치하며, 단백질 코딩 유전자로 식세포작용 및 $\mathrm{T}$ cell receptor (TCR)의 신호 전달에 관련이 있다. CD3zeta chain은 $\mathrm{TCR}$ 신호 전달에 관여하는 경로에서 중요한 역할을 하 고, $\mathrm{CD} 3 \zeta$ chain의 downregulation은 만성 염증과 관련이 있 다(Rieux-Laucat et al., 2006; Barbara Érsek et al., 2012). 또한 Somatic $\mathrm{CD} 3 \zeta$ 돌연변이는 면역 기능을 손상시킨다고 보 고하였다(Rieux-Laucat et al., 2006). TCR 신호 전달 분자에 서 단백질이 감소하게 되면 그 단백질의 발현이 면역 기 능의 장애와 상관관계가 있다는 점, 즉 결핵균 감염 시 $\mathrm{CD} 3 \zeta$ chain의 단백질 발현이 감소하는 것도 확인하였다 (Seitzer et al., 2001). 또 다른 $\mathrm{CD} 3 \zeta$ chain과 관련된 연구에 서는, $\mathrm{CD} 3 \zeta$ chain을 갖는 Chimeric Antigen Receptor (CAR) $\mathrm{T}$ cell이 $\mathrm{T}$ cell의 활성화 및 종양 세포를 사멸시키는데 효 과적으로 작용한다고 밝혔다(Zhang et al., 2017).

따라서 본 연구는 한국인 유전체 역학 조사 사업의 일 환으로 구성되어 있는 코호트 자료를 활용하여 결핵 환 자군과 건강 대조군 사이에 CD247 유전자의 유전적 다 형성이 결핵 발병에 영향을 주었는지 확인하기 위해 유전 적 변이에 대한 관련성 분석 연구를 실시하였다.

\section{재료 및 방법}

\section{연구대상자}

본 연구에서 한국인 연구대상자는 한국인 유전체 역학 조사 사업(Korean Genome and Epidermiology Study; KoGES) 의 일환인 Korean Association Resource (KARE)를 기반으로 하였다(Cho et al., 2009). 이 때 사용한 유전체 자료는 질 병관리본부 인체자원은행에서 분양을 받아 분석에 사용 하였다(17070301-01-01). 본 연구에서 사용한 연구대상자 의 선별은 이전 연구와 동일하게 설정하였다(Jin and Park, 2017). 요약하면 환자군은 과거에 결핵 진단을 받은 적이 있는 443명을 대상으로, 건강 대조군은 특별한 질환이 없 는 3,228 명을 대상으로 선정하였다. 결핵 환자군과 건강 대조군의 평균 나이는 각각 51.0세, 51.6세이며, 유의한 차 이는 없었다. 본 연구에서 활용한 유전 정보는 질병관리 본부(KNIH)와 호서대학교에서 연구윤리 승인을 받은 후 분석을 수행하였다(1041231-170418-HR-056-02).

\section{유전형 분석과 SNP 선별}

본 연구에서 분석한 $C D 247$ 유전자의 전사체 영역에
존재하는 7개의 Single nucleotide polymorphisms (SNPs) 은 KARE 유전형 자료를 통해 선별하였고, 유전자 전사 체 영역의 양 말단에서 $5 \mathrm{~kb}$ 씩 확장하여 이 범위에 존재 하는 $\mathrm{SNP}$ 를 대상으로 분석을 실시하였다. 선별된 $\mathrm{SNP}$ 의 염색체 상 위치는 UCSC Genome Browser on Human Feb. 2009 (GRCh37/hg19)를 기준으로 하였다. 뿐만 아니라 149 개의 imputed SNP를 활용하여 분석에 사용하였다. Imputation은 HapMap database (release 24) (International HapMap Consortium 2003)에서 중국인과 일본인을 참고로 진행하였다. Imputed SNPs는 Minor Allele Frequency (MAF) 가 $1 \%$ 미만이거나 상관계수 $\left(r^{2}\right)$ 가 0.5 미만인 $\mathrm{SNP}$ 는 제 외하였다.

\section{상관성 분석과 통계 분석}

본 연구의 통계 분석은 PLINK version 1.9 (https://www. cog-genomics.org/plink2/)를 사용하였다. 결핵 환자군과 건 강 대조군의 유전적 변이에 대한 상관성 분석은 로지스 틱 회귀 분석을 사용하였고, additive genetic model을 기반 으로 하였다. 분석 시 유의 수준은 0.05 이하를 기준으로 실시하였다. 또한 Haploview version 4.2 (Whitehead Institute for Biomedical Research, Cambridge, MA, USA) 프로그램 을 사용하여 KARE 유전형 정보를 바탕으로 연관불균형 (linkage disequilibrium) 블록 구조를 확인하였다. CD247의 결핵 발생과 관련한 생물학적 기전을 검색하기 위해서 KEGG (Kyoto Encyclopedia of Genes and Genomes, www.genome.jp/kegg/pathway.html) database를 사용하여 결핵에 미치는 영향을 확인하였다.

\section{결 과}

\section{$C D 247$ 유전자 영역의 SNP 선별과 상관성 분석 결과}

GRCh human genome build 37를 기준으로 염색체 1번에 서 $C D 247$ 유전자의 전사체 영역에서 양방향으로 $5 \mathrm{~kb}$ 씩 확장하여 KARE 유전형 자료에서 13 개의 genotyped SNPs (rs16859030, rs2480679, rs2280635, rs1773560, rs2293325, rs1214596, rs1214611, rs858554, rs12259466, rs863455, rs$10918702, \mathrm{rs} 1737502, \mathrm{rs} 1737501)$ 을 확인하였다. 이렇게 선 별된 $C D 247$ 유전자의 13 개 $\mathrm{SNPs}$ 을 대상으로 결핵 환자 군과 건강인 대조군에 대한 로지스틱 회귀 분석을 시행 한 결과 2 개의 $\mathrm{SNP}$ 에서 통계적으로 유의한 상관관계 $(P<$ $0.05)$ 를 볼 수 있었다. 가장 높은 유의 수준 $(P=0.031)$ 을 보 이는 $\mathrm{SNP}$ 은 $\mathrm{rs} 863455$ 이며 상대적 위험도(OR)는 1.17 , 신 
뢰구간 $(95 \% \mathrm{CI})$ 은 $1.01 \sim 1.35$ 를 나타냈다. $\mathrm{rs} 863455$ 의 $\mathrm{MAF}$ 를 살펴보면, 결핵 환자군에서는 C 염기의 빈도가 $39 \%$ 이고, 건강 대조군에서는 $35 \%$ 로 약 $4 \%$ 의 빈도 차이가 있어 rs863455의 $\mathrm{C}$ 염기를 보유한 그룹의 $\mathrm{T}$ 염기를 보유 한 그룹에 비해 결핵 발생의 위험도가 높아진다는 것을 알 수 있었다. 또 다른 유의한 결과를 보이는 rs10918702 도 minor allele인 A 염기를 보유할 경우에 결핵 발생이 높
아지는 것을 확인하였다(Table 1).

\section{CD247 유전자 SNP imputation 후 상관성 분석 결과}

$\mathrm{KARE}$ 유전형 자료를 기반으로 $C D 247$ 유전자의 SNPs imputation을 실시하여 더 많은 SNPs과 결핵의 상관성 여 부를 확인해 보았다. 그 결과 149 개의 SNP이 확인되었고 그 중 7 개의 $\mathrm{SNP}$ 이 통계적으로 유의하였다. 가장 높은

Table 1. Results of the case-control association analysis between the 13 SNPs in the $C D 247$ gene on chromosome 1 and tuberculosis in the KARE subjects

\begin{tabular}{|c|c|c|c|c|c|c|c|c|c|}
\hline \multirow[b]{2}{*}{ No. } & \multirow[b]{2}{*}{ SNP } & \multirow[b]{2}{*}{$\mathrm{BP}$} & \multirow[b]{2}{*}{ Function } & \multirow[b]{2}{*}{ A1 } & \multirow[b]{2}{*}{ A2 } & \multicolumn{2}{|c|}{ MAF } & \multirow[b]{2}{*}{ OR $(95 \% \mathrm{CI})$} & \multirow{2}{*}{$\begin{array}{l}\text { Additive } \\
P \text { value }\end{array}$} \\
\hline & & & & & & $\begin{array}{c}\text { Cases } \\
(\mathrm{n}=443)\end{array}$ & $\begin{array}{c}\text { Controls } \\
(\mathrm{n}=3,228)\end{array}$ & & \\
\hline 1 & rs16859030 & 167401254 & Intronic & $\mathrm{T}$ & $\mathrm{C}$ & 0.245 & 0.251 & $0.97(0.82 \sim 1.14)$ & 0.722 \\
\hline 2 & rs2480679 & 167407517 & Intronic & A & G & 0.183 & 0.180 & $1.02(0.85 \sim 1.23)$ & 0.775 \\
\hline 3 & rs2280635 & 167410391 & Intronic & $\mathrm{C}$ & $\mathrm{T}$ & 0.221 & 0.211 & $1.06(0.89 \sim 1.26)$ & 0.472 \\
\hline 4 & rs1773560 & 167421763 & Intronic & G & A & 0.146 & 0.138 & $1.06(0.87 \sim 1.30)$ & 0.536 \\
\hline 5 & rs2293325 & 167426146 & Intronic & $\mathrm{T}$ & $\mathrm{C}$ & 0.214 & 0.234 & $0.89(0.75 \sim 1.06)$ & 0.214 \\
\hline 6 & rs1214596 & 167427170 & Intronic & A & $\mathrm{T}$ & 0.096 & 0.083 & $1.17(0.92 \sim 1.50)$ & 0.184 \\
\hline 7 & rs1214611 & 167449104 & Intronic & A & G & 0.428 & 0.418 & $1.04(0.90 \sim 1.20)$ & 0.542 \\
\hline 8 & rs858554 & 167454914 & Intronic & A & G & 0.152 & 0.150 & $1.05(0.86 \sim 1.27)$ & 0.613 \\
\hline 9 & rs858553 & 167455145 & Intronic & A & G & 0.152 & 0.150 & $1.05(0.86 \sim 1.27)$ & 0.617 \\
\hline 10 & rs863455 & 167457824 & Intronic & $\mathrm{C}$ & $\mathrm{T}$ & 0.395 & 0.356 & $1.17(1.01 \sim 1.35)$ & $\underline{0.0319}$ \\
\hline 11 & rs10918702 & 167458092 & Intronic & A & G & 0.069 & 0.052 & $1.35(1.02 \sim 1.78)$ & $\underline{0.0343}$ \\
\hline 12 & rs 1737502 & 167485635 & Intronic & $\mathrm{C}$ & A & 0.134 & 0.138 & $0.98(0.80 \sim 1.20)$ & 0.872 \\
\hline 13 & rs1737501 & 167485762 & Intronic & A & $\mathrm{T}$ & 0.134 & 0.138 & $0.98(0.80 \sim 1.20)$ & 0.872 \\
\hline
\end{tabular}

$P$-values $<0.05$ are indicated in bold. Abbreviations: SNP, single nucleotide polymorphism; BP, base pair; A1, minor allele; A2, major allele; MAF, minor allele frequency; CI, confidence interval; OR, odds ratio; The SNP positions are based on the GRCh Build 37 human genome assembly

Table 2. Results of the case-control association analysis between imputed SNPs in the in the CD247 gene on chromosome 1 and tuberculosis in the KARE subjects (Result $P<0.05$ )

\begin{tabular}{|c|c|c|c|c|c|c|c|c|c|}
\hline \multirow[b]{2}{*}{ No. } & \multirow[b]{2}{*}{ SNP } & \multirow[b]{2}{*}{ BP } & \multirow[b]{2}{*}{ Function } & \multirow[b]{2}{*}{ A1 } & \multirow[b]{2}{*}{$\mathrm{A} 2$} & \multicolumn{2}{|c|}{ MAF } & \multirow[b]{2}{*}{ OR $(95 \% \mathrm{CI})$} & \multirow{2}{*}{$\begin{array}{l}{ }^{*} \text { Additive } \\
P \text { value }\end{array}$} \\
\hline & & & & & & $\begin{array}{c}\text { Cases } \\
(\mathrm{n}=443)\end{array}$ & $\begin{array}{c}\text { Controls } \\
(\mathrm{n}=3,228)\end{array}$ & & \\
\hline G1 & rs863455 & 167457824 & Intronic & $\mathrm{C}$ & $\mathrm{T}$ & 0.395 & 0.356 & $1.17(1.01 \sim 1.35)$ & 0.032 \\
\hline $\mathrm{G} 2$ & rs10918702 & 167458092 & Intronic & A & $\mathrm{G}$ & 0.069 & 0.052 & $1.35(1.02 \sim 1.78)$ & 0.034 \\
\hline I1 & rs10918703 & 167460662 & Intronic & A & G & 0.068 & 0.050 & $1.35(1.02 \sim 1.80)$ & 0.033 \\
\hline $\mathrm{I} 2$ & rs10918704 & 167460663 & Intronic & A & G & 0.068 & 0.050 & $1.35(1.02 \sim 1.80)$ & 0.033 \\
\hline $\mathrm{I} 3$ & rs858545 & 167461391 & Intronic & A & $\mathrm{C}$ & 0.339 & 0.295 & $1.22(1.05 \sim 1.42)$ & 0.009 \\
\hline I4 & rs704848 & 167461873 & Intronic & $\mathrm{C}$ & G & 0.388 & 0.350 & $1.16(1.01 \sim 1.34)$ & 0.036 \\
\hline I5 & rs704849 & 167462304 & Intronic & $\mathrm{G}$ & $\mathrm{C}$ & 0.388 & 0.350 & $1.16(1.01 \sim 1.34)$ & 0.036 \\
\hline
\end{tabular}

*All data were selected with $P$-values $<0.05$. Abbreviations: G of no., genotyped number of SNP; I of no., imputed number of SNP; SNP, single nucleotide polymorphism; BP, base pair; A1, minor allele; A2, major allele; MAF, minor allele frequency; OR, odds ratio; CI, confidence interval; The SNP positions are based on the GRCh Build 37 human genome assembly 
유의 수준 $(P=0.009)$ 을 보이는 $\mathrm{SNP}$ 은 $\mathrm{rs} 858545$ 이며 상대 적 위험도 $(\mathrm{OR})$ 는 1.22 , 신뢰구간 $(95 \% \mathrm{CI})$ 은 $1.05 \sim 1.42$ 를 나타냈다. rs858545의 MAF를 살펴보면, 결핵 환자군에서 는 A 염기의 빈도가 $33 \%$ 이고, 건강 대조군에서는 $29 \%$ 로 약 $4 \%$ 의 빈도 차이가 있어 $\mathrm{rs} 858545$ 의 $\mathrm{A}$ 염기를 보유할 경우에 결핵 발생을 증가시키는 방향으로의 상관성이 있 는 것을 알 수 있었다. Imputation을 실시하기 전 분석 결
과는 결핵 발병과 상대적 위험도가 낮은 $\mathrm{SNPs}$ 이 존재하 였지만 imputation을 실시한 후 분석 결과는 모든 SNPs에 서 상대적 위험도가 높게 나타났다(Table 2).

\section{$C D 247$ 유전자의 SNP이 유전자와 단백질 발현에 미치} 는 영향

Imputation을 실시한 후 유의성이 높은 $C D 247$ 유전자의

Table 3. Results of the Regulome DB of imputed SNPs in CD247 gene on chromosome 1

\begin{tabular}{|c|c|c|c|c|c|c|c|c|}
\hline \multirow{2}{*}{ SNP } & \multirow{2}{*}{$\mathrm{BP}$} & \multirow{2}{*}{$\mathrm{A} 1$} & \multirow{2}{*}{$\mathrm{A} 2$} & \multicolumn{5}{|c|}{ Regulome DB } \\
\hline & & & & Score & TFBS & DNase & Proteins bound & Motif \\
\hline rs 863455 & 167457824 & $\mathrm{C}$ & $\mathrm{T}$ & 6 & + & + & - & c-Ets-1, SPDEF \\
\hline rs10918702 & 167458092 & A & $\mathrm{G}$ & 4 & + & + & TCF7L2 & - \\
\hline rs10918703 & 167460662 & A & G & - & - & - & - & - \\
\hline rs10918704 & 167460663 & A & G & - & - & - & - & - \\
\hline rs858545 & 167461391 & A & $\mathrm{C}$ & $2 b$ & + & + & CEBPB, E2F6, ELF1 & HNF3, FOXO1 \\
\hline rs704848 & 167461873 & $\mathrm{C}$ & G & 5 & + & + & - & PLAG1 \\
\hline rs704849 & 167462304 & $\mathrm{G}$ & $\mathrm{C}$ & 6 & + & + & - & FOXM1 \\
\hline
\end{tabular}

Abbreviations: SNP, single nucleotide polymorphism; BP, base pair; A1, minor allele; A2, major allele; TFBS, transcription binding factor site; +. affect; - , no data. The SNP positions are based on the on the GRCh Build 37 human genome assembly

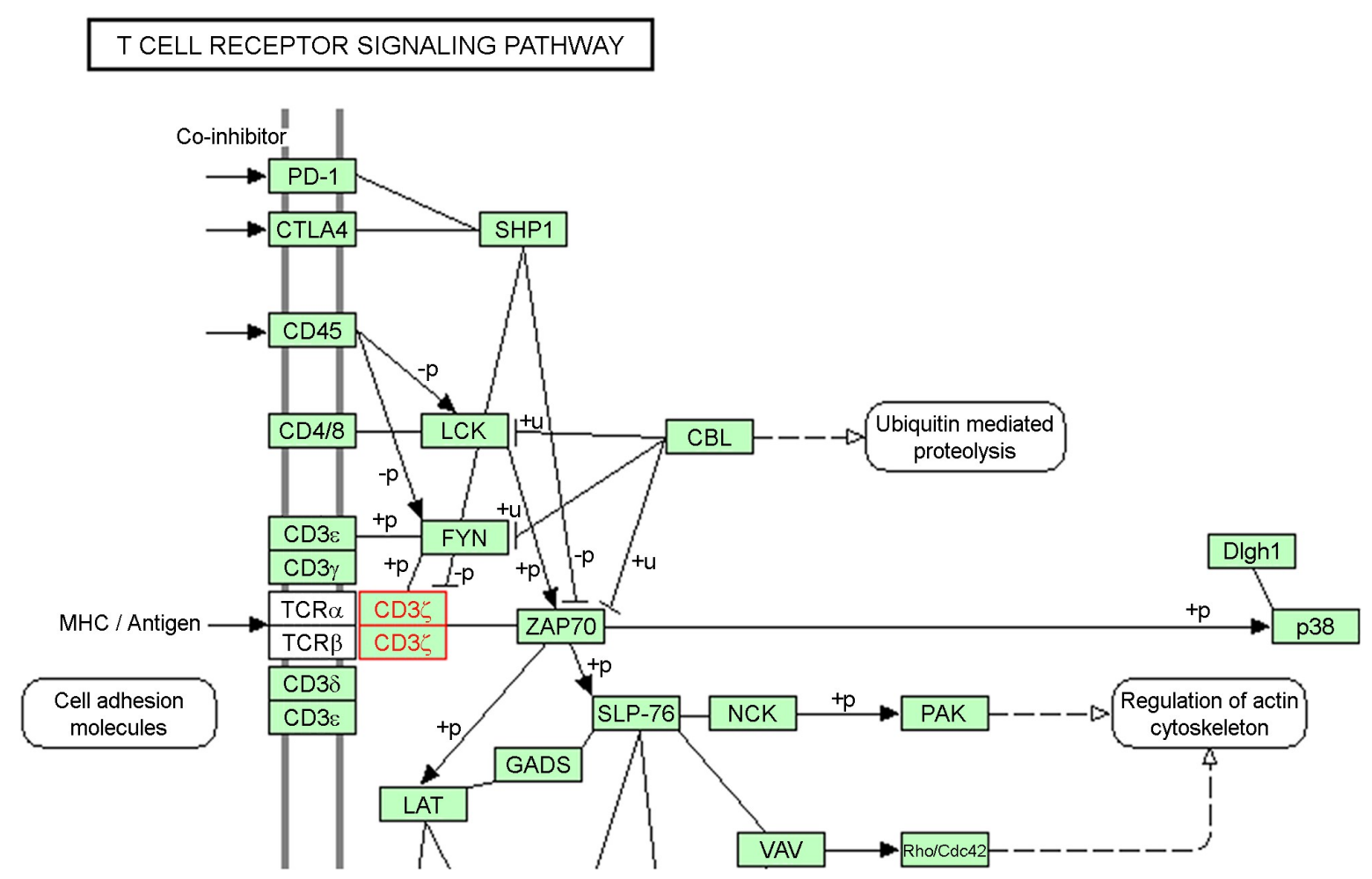

Fig. 1. The KEGG signaling pathway for the part of cell adhesion molecules. CD247 found in T cell receptor signaling pathway according to KEGG is red. The interaction partners of CD247 are TCR $\alpha$, TCR $\beta$ and ZAP70. 
$\mathrm{SNP}$ 가 어떻게 유전자 혹은 단백질 발현에서 영향을 미 치는지 Regulome-DB (http://www.regulomedb.org/index)에서 확인해 보았다. 그 결과 rs858545에서 의미 있는 score를 확인하였다. rs858545는 전사 인자 결합 반응에 영향을 주 고 DNase peak 차이가 있다는 것을 확인하였다. 또한 $\mathrm{HNF} 3, \mathrm{FOXO} 1$ 의 motif로 작용하여 $\mathrm{CD} 247$ 유전자 발현에 영향을 줄 수 있다(Table 3 ).

\section{$C D 247$ 유전자의 KEGG pathway 검색 결과}

$C D 247$ 유전자의 결핵 발생 관련성에 대해 생물학적 기 전의 관점에서 살펴보고자 $\mathrm{KEGG}$ database를 검색한 결과 $\mathrm{T}$ cell receptor signaling pathway에 관여하는 것을 확인하였 다. $\mathrm{TCR} \alpha$ 와 $\mathrm{TCR} \beta$ 의 $\mathrm{CD} 3$ complex 에 속하는 $\mathrm{CD} 3$ 와 탈 인산화 및 인산화 작용이 일어난 $\mathrm{CD} 45$ 가 $\mathrm{LCK}$ 및 $\mathrm{FYN}$ 을 개방시키고 ZAP70에 대한 상호작용을 통해 T Cell receptor signaling pathway에 관여하고 있는 것을 확인할 수 있었다 (Fig. 1).

\section{고 찰}

Mycobacterium tuberculosis는 전 세계적으로 많은 사망을 유발하고 있고, 결핵 발생은 선천 면역 혹은 적응 면역에 의해 균이 제거되거나 감염이 발생한다(Nemes et al., 2018). 본 연구에서는 이러한 결핵의 발생에 대한 유전적 요인 의 연관성을 살펴보았다. $C D 247$ 유전자의 imputed SNPs에 서 결핵 환자군과 건강 대조군의 $\mathrm{MAF}$ 차이에 따른 통계 적 유의성을 분석하고, 유전적 변이에 따른 결핵 발생의 상관성을 분석한 결과 7 개의 $\mathrm{SNPs}$ 에서 통계적으로 유의 한 수준의 빈도 차이가 있는 것을 확인할 수 있었다. 그 중 가장 높은 유의 수준을 보인 rs858545의 경우 A 염기 를 보유한 경우에 결핵의 상대적 위험도가 1.22 로 높아지 는 것을 확인할 수 있었고, 또한 rs863455은 minor allele 인 $\mathrm{C}$ 염기를 가질 경우에 결핵에 대한 상대적 위험도가 1.17 로 높아지는 것을 확인할 수 있었다. 따라서 기존의 KARE 자료에서 imputation 후의 SNPs을 기준으로 CD247 유전자의 통계적 유의성을 분석한 결과 imputation 전의 결과보다 많은 SNPs을 선별할 수 있었고, 높은 유의성을 갖는 SNP도 확인하였다. 이런 imputed SNPs 7개가 어떻 게 $C D 247$ 유전자 혹은 단백질에 영향을 미치는 지 확인 하기 위해 Regulome $\mathrm{DB}$ 를 이용하여 살펴보았고, 그 결 과 통계적 유의성이 가장 높고, 의미 있는 점수를 갖는 rs858545가 전사 인자 결합에 대한 영향을 주고, DNase에
대한 반응 차이가 있다는 것을 확인하였다.

결핵 발병의 생물학적 기전으로 살펴보면 $\mathrm{CD} 4^{+} \mathrm{T}$ cell은 결핵균 감염에 저항하는 인간의 능력에 중요한 역할을 한 다고 알려져 있다(Du et al., 2010). T cell과 감염된 대식 세 포의 상호작용은 M. tuberculosis에 대한 방어 면역의 핵심 이고, $\mathrm{CD}^{+} \mathrm{T}$ cell은 이러한 방어 면역에 있어 필수적인 역 할을 하지만 $\mathrm{CD}^{+}, \gamma \delta \mathrm{T}$ cell 및 $\mathrm{CD} 1$-restricted $\mathrm{T}$ cell과 같 은 다른 $\mathrm{T}$ cell subsets에 의해 도움을 받는다(Boom et al., 2003). 방어 면역에 필수적인 $\mathrm{CD}^{+} \mathrm{T}$ cell을 활성화시키 기 위해 $\mathrm{T}$ cell receptor의 작용이 필요하다. 따라서 $\mathrm{T}$ cell receptor의 $\alpha, \beta$ chain이 4 개의 $\mathrm{CD} 3$ subunit $(\varepsilon, \gamma, \delta, \zeta)$ 과 결합 하여 CD3 complex를 형성하게 된다(Guy and Vignali, 2009). $\mathrm{CD} 3$ complex와 $\mathrm{T}$ cell receptor는 안정적으로 결합하여 $\mathrm{T}$ cell receptor complex를 형성하게 된다. 그 후 $\mathrm{MHC}$ class II에 의해 peptide antigen을 제시 받은 TCR에서 이를 인 식하여 $\mathrm{CD} 3$ chain이 세포 내부로 신호를 전달하여 $\mathrm{T}$ cell activation이 발생한다. 따라서 CD247을 발현하는 유전자 에 유전적인 변이가 일어나게 되면 $\mathrm{CD} 247$ 이 중요한 역 할을 담당하는 $\mathrm{T}$ cell receptor signaling pathway에 이상이 생기게 되고, 이에 따라 면역체계에 변화가 일어날 것이 라고 사료된다.

본 연구는 위의 분석들을 통해 $C D 247$ 의 변이가 결핵 발병에 영향을 줄 수 있다는 가능성을 제시하였다. 따라 서 추가적인 실험을 통해 이러한 결과가 검증된다면, 본 연구의 유의성이 매우 높을 것으로 사료된다.

\section{ACKNOWLEDGEMENT}

This research was supported by Basic Science Research Program through the National Research Foundation of Korea (NRF), funded by Ministry of Sciences, ICT \& Future Planning (2017R1C1B5016589) and Brain Busan 21 Plus project in 2019.

\section{CONFLICT OF INTEREST}

The authors have no conflicts of interest to disclose.

\section{REFERENCES}

Algood HM, Chan J, Flynn JL. Chemokines and tuberculosis. Cytokine Growth Factor Rev. 2003. 14: 467-477.

Boom WH, Canaday DH, Fulton SA, Gehring AJ, Rojas Re, Torres M. Human immunity to M. tuberculosis: T cell subsets and 
antigen processing. Tuberculosis. 2003. 83: 98-106.

Cho YS, Go MJ, Kim YJ, Heo JY, Oh JH, Ban HJ, Yoon D, Lee MH, Kim DJ, Park M, Cha SH, Kim JW, Han BG, Min H, Ahn Y, Park MS, Han HR, Jang HY, Cho EY, Lee JE, Cho NH, Shin C, Park T, Park JW, Lee JK, Cardon L, Clarke G, McCarthy MI, Lee JY, Lee JK, Oh B, Kim HL. A large-scale genome-wide association study of Asian populations uncovers genetic factors influencing eight quantitative traits. Nat Genet. 2009. 41: 527-534.

Du G, Chen CY, Shen Y, Qiu L, Huang D, Wang R, Chen ZW. TCR repertoire, clonal dominance, and pulmonary trafficking of mycobacterium-specific $\mathrm{CD} 4^{+}$and $\mathrm{CD}^{+} \mathrm{T}$ effector cells in immunity against tuberculosis. J Immunol. 2010. 185: 3940 -3947 .

Érsek B, Molnár V, Balogh A, Matkó J, Cope AP, Buzás EI, Falus A, Nagy G. CD3ל-Chain Expression of Human T Lymphocytes Is Regulated by TNF via Src-like Adaptor Protein-Dependent Proteasomal Degradation. J Immunol. 2012. 189: 1602-1610.

Fogel N. Tuberculosis: a disease without boundaries. Tuberculosis. 2015. 95: 527-531.

Guy CS, Vignali DA. Organization of proximal signal initiation at the TCR:CD3 complex. Immunol Rev. 2009. 232: 7-21.

Harishankar M, Selvaraj P, Bethunaickan R. Influence of Genetic Polymorphism Towards Pulmonary Tuberculosis Susceptibility. Front Med. 2018. 5: 213.

HIRA. Health Insurance Review \& Assessment Service. http:// gisopendata.hira.or.kr/map.do.

Jin HS, Park S. Association of the CD226 Genetic Polymorphisms with Risk of Tuberculosis. Biomedical Science Letters. 2017. 23: 89-95.
Min J, Kim JS, Kim HW, Shin AY, Koo HK, Lee SS, Kim YK, Shin KC, Chang JH, Chun G, Lee J, Park MS, Park JS. Clinical profiles of early and tuberculosis-related mortality in South Korea between 2015 and 2017: a cross-sectional study. BMC Infect Dis. 2019. 19: 735.

Nemes E, Geldenhuys H, Rozot V, Rutkowski KT, Ratangee F, Bilek N, Mabwe S, Makhethe L, Erasmus M, Toefy A, Mulenga H, Hanekom WA, Self SG, Bekker LG, Ryall R, Gurunathan S, DiazGranados CA, Andersen P, Kromann I, Evans T, Ellis RD, Landry B, Hokey DA, Hopkins R, Ginsberg AM, Scriba TJ, Hatherill M. Prevention of M. tuberculosis Infection with H4:IC31 Vaccine or BCG Revaccination. N Engl J Med. 2018. 379: 138-149.

Rieux-Laucat F, Hivroz C, Lim A, Mateo V, Pellier I, Selz F, Fischer A, Le Deist F. Inherited and somatic CD3zeta mutations in a patient with T-cell deficiency. N Engl J Med. 2006. 354: 1913-1921.

Seitzer U, Kayser K, Höhn H, Wacker HH, Ploetz S, Flad HD,

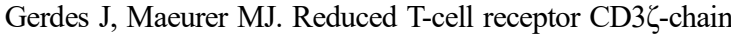
protein and sustained $\mathrm{CD} 3 \varepsilon$ expression at the site of mycobacterial infection. Immunology. 2001. 104: 269-277.

Zhang C, Liu J, Zhong JF, Zhang X. Engineering CAR-T cells. Biomark Res. 2017. 5: 22.

https://doi.org/10.15616/BSL.2020.26.1.22

Cite this article as: $\mathrm{Ju}$ Y, Kim SS, Lee KE, Park S, Jin H. Association of the Genetic Polymorphisms for CD247 Gene and Tuberculosis Case. Biomedical Science Letters. 2020. 26: 22-27. 